\title{
Historia
}

\section{Un pionero de la historiografía médica de la antiguiedad: Rodolfo del Castillo y Quartiellers (1845-1917)}

\author{
A pionner of medical historiography in antiquity: \\ Rodolfo del Castillo-Quartiellers (1845-1917)
}

\section{Um pioneiro da historiografia médica da antiguidade: Rodolfo del Castillo y Quartiellers (1845-1917)}

Francisco Herrera Rodríguez

Catedrático E.U. Facultad de Enfermería y Fisioterapia. Universidad de Cádiz.

Cómo citar este artículo en edición digital: Herrera Rodríguez, F. (2013) Un pionero de la historiografía médica de la antigüedad: Rodolfo del Castillo y Quartiellers (1845-1917). 17, 35. Disponible en: http://dx.doi.org/10.7184/cuid.2013.35.03

Correspondencia: Facultad de Enfermería y Fisioterapia - Cádiz - Av. Ana de Viya 5211009.

Correo electrónico: francisco.herrera@uca.es

Recibido 11/12/2012. Aceptado 04/02/2013.

A la memoria de Antonio Orozco Acuaviva

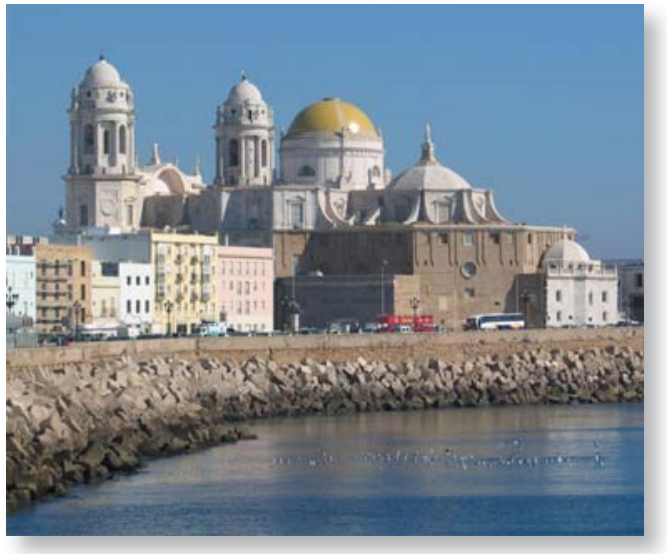

ABSTRACT

This paper intends to be a biographic summary of Rodolfo del Castillo-Quartiellers (1845-1917), a famous ophthalmologist from Cádiz and renowned follower of Spanish medical positivism tendencies. A particular analysis of his major publications in the field of medical historiography in antiquity is also pre- sented, focusing on his study about the Code of Hammurabi as well as on Egiptian, Greek and Roman medicines.

Keywords: History of ophthalmology, Code of Hammurabi, ancient Egipt, classical Greece, ancient Rome.

\section{RESUMO}

Neste artigo, vamos fazer uma breve biografia de Cádiz médico Rodolfo del Castillo e Quartiellers (1845-1917), o positivismo oftalmologista famoso médico espanhol, apresentando também um estudo de suas principais publicações no campo da historiografia médica da antiguidade, destacando o seu trabalho sobre o Código de Hamurabi ou egípcia medicamentos, grega e romana.

Palavras-chave: História de Oftalmologia, Código de Hamurabi, o antigo Egito, na Grécia antiga, Roma antiga. 


\section{RESUMEN}

En este artículo realizamos una síntesis biográfica del médico gaditano Rodolfo del Castillo y Quartiellers (1845-1917), afamado oftalmólogo del positivismo médico español, presentando además un estudio sobre sus principales publicaciones en el terreno de la historiografía médica de la Antigüedad, destacando sus trabajos sobre el Código de Hammurabi o las medicinas egipcia, griega y romana.

Palabras clave: Historia de la Oftalmología, Código de Hammurabi, Egipto Antiguo, Grecia clásica, Roma clásica.

\section{SÍNTESIS BIOGRÁFICA}

Rodolfo del Castillo y Quartiellers nació en Cádiz el 9 de noviembre de 1845, pasó su infancia en Gibraltar y consiguió el grado de Bachiller en Artes en Cádiz en 1869, teniendo en el Instituto como maestro a Romualdo Álvarez Espino, miembro destacado del krausismo gaditano (Orozco, 1996). En el curso 1869-70, en pleno sexenio revolucionario, comenzó sus estudios en la Facultad de Medicina de Cádiz; en apenas tres años, aprovechando las circunstancias de la época que favorecían poderse examinar de un buen número de materias en el mismo curso académico, obtuvo el grado de licenciado en febrero y marzo de 1872. Dos meses después, en el mes de junio, superó las asignaturas del doctorado (Historia de las Ciencias
Médicas y Análisis Químico), y defendió su tesis doctoral sobre "Sífilis, naturaleza y sitio".

Se inició en la oftalmología con su pariente Cayetano del Toro y Quartiellers (1842-1915), que por esas fechas había abierto una cátedra libre de oftalmología en la calle Argantonio de Cádiz. Orozco es el autor que con más detalle ha estudiado el periplo académico y científico de Rodolfo del Castillo, y gracias a sus investigaciones sabemos que realizó una importante tarea en la primera revista española de la especialidad, La Crónica Oftalmológica, fundada por el citado Cayetano del Toro. En 1872 viajó a Londres para profundizar en sus conocimientos oftalmológicos junto a William Bowman, luego se desplazó a París para hacer lo propio con Salvador Fano, Fernand Giraud y Xavier Galezowski (Orozco, 1996). Durante unos meses de 1873 dirigió el balneario de Artegio en La Coruña, hasta que en ese mismo año se estableció en Córdoba, ciudad en la que desarrolló una importante actividad clínica y publicística, dirigiendo "La Andalucía Médica”.

En 1893 fue elegido Diputado y se trasladó a Madrid donde el cirujano portuense Federico Rubio y Gali (1827-1902) le ofreció una plaza de profesor de Enfermedades de los Ojos en el afamado Instituto de Terapéutica Operatoria (Orozco, 1996). Fue socio fundador de la Sociedad Oftalmológica Hispano-Americana y en 1913 fundó en Madrid el Instituto Médico-Quirúrgico de la Encarnación. Del Castillo tuvo también una especial dedicación a la investigación histórica, no en vano fue Correspondiente de la Real Academia de la Historia, destacando sus estudios sobre la medicina en la Cultura asirio-babilónica (Herrera, 1987), y sobre las medicinas egipcia, griega y romana, de los que realizó también una síntesis el profesor Orozco Acuaviva. 
El objetivo pues de este artículo es analizar su obra historiográfica, por eso haremos hincapié en los que dedicó al Código de Hammurabi, al embalsamamiento en el Egipto Antiguo y a la oftalmología en Grecia y en Roma, entre otros; todo lo cual nos dará la dimensión de Rodolfo del Castillo como uno de los pioneros en España de la historiografía médica de la Antigüedad.

\section{EL CÓDIGO DE HAMMURABI Y LA OF-} TALMOLOGÍA EN BABILONIA

"El Código de Hammurabi y la oftalmología en los tiempos babilónicos" fue publicado por Rodolfo del Castillo en el año 1904. Hay que tener en cuenta la fecha de la publicación para comprender que el médico gaditano estaba muy pendiente de la bibliografía internacional relacionada con la historia antigua, ya que el hallazgo realizado por la expedición científica francesa en las ruinas de Susa, liderada por M.J. Morgan, del Código de Hammurabi fue llevado a cabo entre el mes de diciembre de 1901 y enero de 1902. Josep Padró afirma que con la época de Hammurabi se tiene la sensación de asistir a un gran cambio de rumbo de la Historia; hoy se tiende a considerar que este rey promulgó en el cuadragésimo año de su reinado un conjunto de leyes que mandó grabar en estelas de piedra y repartirlas por las capitales de su Imperio. Este monumento, como es sabido, posee inscripciones de carácter cuneiforme y un bajorrelieve en que aparecen dos personajes: uno sentado, Schamach o Samas, dios del Sol, y el otro de pie, que es el rey Hammurabi. En esta escena parece que el dios habla y el rey escucha, lo cual recuerda a Rodolfo del Castillo, como a Gautier, uno de los pasajes del Pentateuco en que Dios habla a Moisés "cara a cara". Pocas veces, dice Laín Entralgo, la condición humana ha sido senti-

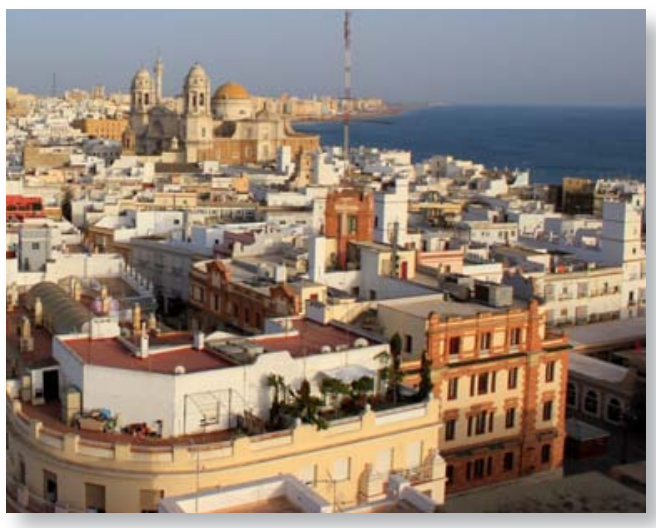

da como permanente sumisión a la divinidad como en Asiria y Babilonia. Recuérdese que los dioses (Marduk, Samas, Ea, Nin Azu, etc.) podían infligir a los hombres el castigo de la enfermedad, de hecho la palabra asiria "shêrtu" significa a la vez pecado, impureza moral, cólera de los dioses, castigo y enfermedad.

Al médico gaditano le interesa la dimensión ético-social del Código de Hammurabi y subraya que "no es una recopilación de leyes sistemáticas ligadas entre sí, sino más bien una agrupación de disposiciones casuísticas de orden civil, penal y administrativo redactadas por un pueblo relativamente civilizado $2000 y$ más años antes de Jesucristo". Aparte de esto, $\mathrm{y}$ de la semejanza que tiene con el Pentateuco, "pues hay pasajes tan exactos, que parecen estar copiados de él", a del Castillo le llama la atención lo que se legisló respecto a los sanitarios. El autor esquematiza la temática de los 282 artículos señalando en cursiva los que atañen a los cirujanos, veterinarios y marcadores, transcribiendo especialmente del 215 al 223, que aunque muy conocidos reproducimos a continuación:

- Si un cirujano ha hecho una operación a un hombre afecto de herida grave con lanceta de bronce, y el hombre curase, si también ha abierto con lanceta de bronce un tumor en un ojo y el ojo curase, recibirá 10 siclos de plata. 
- Si el paciente es un liberto, recibirá 5 siclos de plata.

- Si un cirujano ha hecho una operación a un hombre afecto de herida grave con lanceta de bronce y le produce la muerte, si también ha abierto un tumor en un ojo y el ojo quedase sin visión se le cortará la mano.

- Si un cirujano opera el esclavo de un liberto de herida grave con lanceta de bronce y muriese, restituirá el esclavo.

- Si le abre un tumor en un ojo con lanceta de bronce y el ojo quedase sin visión pagará la mitad del precio del esclavo.

- Si un cirujano asiste un herido grave de fractura de un hueso o de una enfermedad interna y curase, el paciente dará al médico 5 siclos de plata.

- Si se trata de un liberto, abonará 3 siclos de plata.

- Si se tratase de un esclavo, el patrono del esclavo dará al cirujano 2 siclos de plata.

Rodolfo del Castillo opina que los que ejercieron la medicina en Babilonia, "no debieron pertenecer a clases superiores, pues no sólo se les ponía tasa a la práctica de sus operaciones, sino que se les castigaba con penas aflictivas y pecuniarias cuando su intervención en las operaciones quirúrgicas no iba seguida de éxito, pues de haber pertenecido estos médicos a clases elevadas de la sociedad o a casta sacerdotal, de otra suerte les trataran (...)". Sobre este punto autores como Laín Entralgo señalan que en Asiria y Babilonia hubo médicos ("individuos estamentados dedicados a la cura de las enfermedades"), que fueron conocidos con el nombre de asû; pero la visión asirio babilónica de la enfermedad había de imponer un carácter sacerdotal: el bârû o vidente (encargado del interrogatorio y de la adivinación), y el âshipu o exorcista.
Para Laín sólo ciertos prácticos de nivel secundario, como los gallubu o "cirujanos-barberos" debieron tener condición laica. Bishop afirma que eran precisamente los gallubu los que tenían a su cargo la cirugía menor, incluyendo la "odontología" y el herraje de los grilletes de los esclavos. Zaragoza Rubira ha precisado también que la operación quirúrgica era un quehacer artesanal y la labor del médico-sacerdote actos de culto, y por ello quedaban por encima de los reglamentos.

En lo que se refiere al instrumental quirúrgico, aunque en estos tiempos era ya conocido el hierro, se daba preferencia al bronce como material punzante y cortante, por eso se apunta lo siguiente en la monografía del médico gaditano: "...al cual habian conseguido dar un temple y una dureza especial aplicable con tal objeto y que utilizaban para los usos corrientes, sin embargo, hacíanse otros instrumentos, $y$ especialmente para los actos quirúrgicos, de oro, plata, pedernal y hasta de bambú, que se usaban según la categoría o rango social a que pertenecía el operado". Recuérdese que Bishop apuntó que en las excavaciones de Nínive se hallaron diversos instrumentos quirúrgicos de bronce y que Knut Haeger cita también los de obsidiana.

Nuestro autor supone que las afecciones oculares debieron estudiarse en aquellos tiempos "de un modo especial"; aunque un cirujano avezado como él se pregunta: “Pero qué clase de operaciones podían ser éstas, que con lanceta o punzón de bronce practicaban en los ojos aquellos cirujanos?". Por eso se detiene en el vocablo babilónico nagabli que Mari tradujo como tumor, Johnes como absceso corneal y Scheile como catarata. Estas traducciones las somete a crítica:

"En el orden de las suposiciones, no nos atrevemos a creer que se trate de un flemón del 


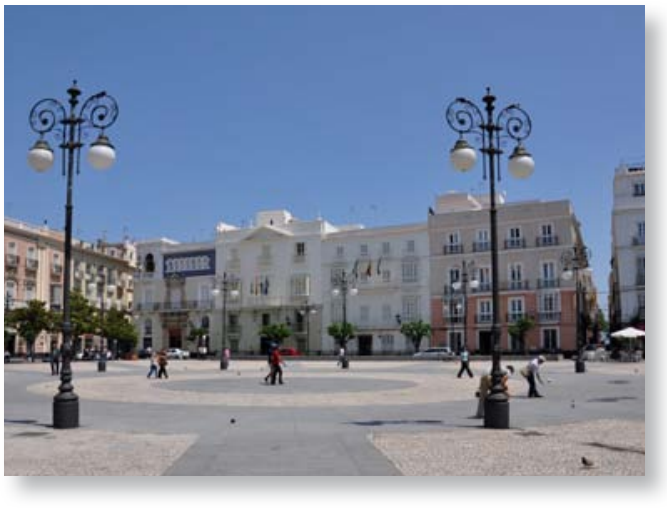

globo ocular, porque en aquellos tiempos es de suponer que la experiencia y la práctica, por muy poca que fuera la de aquellos cirujanos, tendrían la bastante para haberles enseñado que la intervención quirúrgica en estos casos había de ser poco satisfactoria para devolver la visión, y lo mismo se nos ocurre pensar si por tumor tomáramos el estafiloma total o parcial de la córnea. Tampoco es posible creer que se trate de un absceso corneal con o sin derrame de pus en la cámara anterior, porque esto nos haría admitir un refinamiento en la cirugía ocular de aquellos tiempos al nivel de los modernos procedimientos de Soeniche y de Desmarres".

Del Castillo se inclina por la catarata "puesto que esta operación es practicada desde los tiempos más remotos en la India, China y Egipto, llevada allí por los asirios, babilónicos y fenicios, quienes operaban por abatimiento o reclinación”. De todas formas nuestro autor, después de consultar con el doctor Mari y con Fidel Fita, concluye que el significado de esta palabra es una cuestión que queda "en pie y sin precisar".

El médico gaditano afirma que la cirugía se ejercía por separado de la oftalmología, " $y$ muy especialmente la cirugía ocular", que formaba rama independiente, "constituyendo así una verdadera especialidad". Francisco Guerra apunta que no era común la especialización, aunque en tabletas de períodos tardíos se mencionan médicos para los ojos y los animales domésticos. Este autor señala que existen textos que mencionan operaciones del ojo que se han interpretado como de catarata, pero que bien pudieran ser escarificaciones corneales, aunque quizás no se debe descartar el pterigion.

Pensamos que Rodolfo del Castillo era consciente de que estaba haciendo algo novedoso en España con este tipo de estudios historiográficos y por eso dice lo siguiente:

“...al fijar nuestra atención en el monumento de Susa, desde el punto de vista médico, sólo nos ha guiado el interés grande que despierta para la historia de las ciencias médicas y para los que a su estudio se dedican, siguiendo en todo el camino que en el extranjero se viene trazando hace muchos años, y que hoy constituye una rama importante de la arqueología, y que en nuestro país y entre nuestros comprofesores no han tenido aún toda aquella atención que merecen, dando con ello motivo a que se nos crea muy alejados de todo movimiento científico, que se aparta algo de lo especulativo y corriente".

\section{LA PASIÓN POR LA EGIPTOLOGÍA}

Entre 1907 y 1909 nuestro médico se interesó en diversos estudios por el Egipto Antiguo, cabe recordar en este sentido los que dedicó a la esterilización de las aguas del Nilo en el siglo XI, la medicación oleosa en tiempo de los faraones, la momificación y el embalsamamiento o los objetos egipcios encontrados en Tarragona. Cada uno de estos trabajos merece un comentario.

En 1907 publicó "Recuerdos de un viaje a Egipto. La esterilización de las aguas del Nilo en el siglo XI". El título del opúsculo nos avisa de que se trata de una breve crónica de un viaje que arranca con la convicción del médi- 
co gaditano del papel jugado por esta Cultura: “...comunicó los gérmenes de su civilización a Grecia; inició a Moisés en la doctrina de sus santuarios; dio origen a la fusión de los sistemas religiosos y filosóficos de la antigüedad; preparó el nacimiento del cristianismo y fue el lazo que unió el Occidente con el Oriente". En todos sus escritos de carácter historiográfico muestra la erudición de un estudioso de las culturas de la antigüedad; pero a la vez se percibe su apasionamiento, tanto que viaja a Egipto para conocer de primera mano el legado de esta civilización, y buscar y hablar con especialistas que lo ilustren sobre el particular, y esto es precisamente lo que nos sorprende en este breve opúsculo del médico gaditano; por ejemplo en Assuan fue atendido por el doctor Zareef Abadía, médico director del hospital civil, que le facilitó la visita a esta institución asistencial ubicada en la avenida del Nilo. Allí se encuentra con un hospital para 80 enfermos de ambos sexos construido por el sistema de pabellones; el pabellón de hombres lo rodean galerías al descubierto, pero los de las mujeres están cerrados por espesas celosías, "á fin de que aquéllas puedan pasear sin ser vista por los hombres, costumbre musulmana que se lleva aún con mucho rigor". Realiza también algunos apuntes sobre el "Luksor Hospital for Natives"; y cuando esperamos que se extienda sobre esta institución y otras vivencias médicas de su viaje, nos encontramos que se centra en un tema que ha llamado su atención: la esterilización de las aguas del Nilo en el siglo XI, y esto es así porque establece relaciones en El Cairo con el afamado oftalmólogo y humanista Mohamed Eloui Pachá, interesante cultivador de la historia de la medicina que había localizado un manuscrito de Ebn-Raduan, del 460 de la Hegira (1068), sobre la purificación de las aguas del Nilo. Eloui Pachá, salvando las distancias, estableció una comparación entre las ideas de Ebn-Raduan y las de Louis Pasteur. Es sabido que el científico francés preconizó, para sanear completamente el agua, elevar la temperatura a más de $120^{\circ}$ y aún más "porque han observado que hay microbios que resisten temperaturas inferiores". Ebn Raduan, ochocientos años antes, apuntó la necesidad de elevar la temperatura del agua a un alto grado haciéndola hervir y prescribiendo su cocción prolongada, su filtración y exposición posterior al aire de la noche antes de consumirla. Ebn Raduan aprendió por la observación que el agua del Nilo, causante de diversas enfermedades, debía encerrar elementos extraños patógenos y que el mejor medio de desembarazarla de ellos era hacerla filtrar bien y someterla a una temperatura elevada; en una época en que ni la química ni el microscopio podían ayudarle en su labor, preconizó la depuración del agua con sustancias como el tomillo, las almendras amargas, el aneto, la mira, la juncia, y recomendaba el lavado o fumigación de los vasos destinados a contenerla. Este documento de Ebn Raduan le sirve a Rodolfo del Castillo para subrayar la importancia de los estudios histórico médicos, y de camino hacérselo notar a los que miran a esta materia con indiferencia. Lo expresa así:

"Al transcribir íntegro al español el trabajo del Dr. Eloui, lo hacemos, aparte de otras consideraciones que no son del momento, para demostrar una vez más á los que miran con indiferencia los estudios histórico-médicos que éstos merecen más atención que la que ellos le prestan, y que muchas cosas que pasan hoy por novísimas ya nuestros maestros del pasado lo habian conocido y puesto en práctica, y lo que ahora se hace con muchas cosas es cambiarles las vestiduras con sujeción al último figurín, pero los fundamentos son los mismos". 
En 1908 Rodolfo del Castillo, siendo profesor de oftalmología del célebre Instituto Rubio de Madrid, publicó otro folleto titulado " $\mathrm{La}$ medicación oleosa en tiempo de los faraones. El aceite de ricino", de gran interés por las descripciones botánicas y médicas. Parece que el médico gaditano comenzó a recoger información para una obra ambiciosa, de la cual no tenemos noticia que llegara a publicarse, " $\mathrm{La}$ oftalmología en tiempo de los faraones"; en el curso de esta tarea llegó a sus manos el libro de un gran egiptólogo francés, Víctor Loret, titulada "La flora en tiempo de los faraones". Este autor publicó en París, en 1892 la segunda edición de "La flore pharaonique", dedicando aparte un estudio extenso al "Ricinus communis". Precisamente lo que hace Rodolfo del Castillo es divulgar los escritos que sobre este asunto publicó este afamado catedrático de la Universidad de Lyon, con el objetivo de despertar el interés en España por la historiografía médica, dado el atraso existente en este tipo de estudios, que según del Castillo "no es por defectos incorregibles de raza, sino por defecto de educación y preparación". Concreta que el ricino fue conocido "en una época muy remota, puesto que, como veremos, la especie estaba designada por los mismos egipcios desde el siglo XVI, antes de nuestra era, habiendo sido utilizado durante largo tiempo por sus antepasados"; subraya además que el ricino conocido de los antiguos egipcios era el ricino de África o de Arabia, no el ricino de la Índia. Alude también a Herodoto: "los egipcios sacaban el aceite de la planta tanto en caliente, haciendo hervir los granos de agua, tanto en frío". En un papiro descubierto en Egipto, que data del reino de "Ptolomico Philadelpho", se distinguen varias especies de aceites: el aceite de sésamo, el aceite de ricino, el aceite de Cartamo, el aceite de linaza, etc. Señala el médico gaditano a
J. Passalacqua como el primero que en 1826 apuntó la presencia del ricino en las tumbas egipcias antiguas; destacando también el estudio de 1895 de V. Loret y J. Poisson titulado "Etudes de botanique égyptienne. Les végétaux antiques du Musée égyptien du Louvre”. F. Unger, en 1859, declaró haber encontrado en el Museo Egipcio de Viena un grano de esta planta, concretamente la representación del ricino en los bajorrelieves de Tebas y de Tellel-Amarna; pero Víctor Loret mostró su crítica considerando que una de las representaciones es "absolutamente convencional" y la otra parece representar una higuera más que un ricino. Loret como se puede apreciar es un historiador cauto y por eso se expresa así:

"Estos diversos granos de ricino, hallados en las tumbas egipcias, no nos suministran, por desgracia, informes más precisos sobre la antigüedad de la planta en Egipto, que los suministrados por los autores clásicos. En efecto, no sabemos ni por quién han sido descubiertos estos granos, ni dónde, ni en qué condiciones. Las tumbas en las cuales han sido hallados esos granos ¿eran vírgenes? ¿habian sido visitadas $y$ registradas? ¿fueron habitadas por árabes? ¿eran de época faraónica, greco-romana, ó bizantina? Concibese que, en la duda, seria temerario tratar de inferir alguna conclusión clara de la presencia de granos de ricino en los Museos egipcios. A lo sumo, podemos suponer, poniendo en ello cierto optimismo, que algunos de estos granos son realmente antiguos. Pero antiguo, tratándose de Egipto, es un término de valor completamente relativo, $y$, en suma, los granos de ricino de nuestros Museos no nos llevan de modo cierto, más allá que el texto de Herodoto".

Buena parte de esta obra firmada por Rodolfo del Castillo, que se apoya en los estudios de Loret, se dedica al papiro de Ebers, documento en el que se menciona en muchas oca- 
siones al ricino, destacando entre otros los siguientes casos relacionados con la terapéutica:

a) Evacuar el vientre y quitar los cólicos: "Granos de ricino. Comer, hacer pasar con cerveza para que salga todo lo que hay en el vientre".

b) Llagas y ulceraciones: "Aceite sacado de los granos del ricino. Se unge con él a la persona a quien llagas vivas con ulceraciones purulentas hacen sufrir".

c) Dolores: "Granos de ricino. Aplastar y amasar. Poner en miel. Aplicar sobre el miembro paciente".

John F. Nunn, en su obra "La medicina del antiguo Egipto", ha compilado las drogas que parecen haber sido empleadas como laxantes, citando claro está al fruto del ricino, pero también el dátil, el higo, la hierba de papiro, el ajenjo, el cilantro, el comino, el enebro, etc.

En 1908, Rodolfo del Castillo, publicó " $R e$ cuerdos de un viaje a Egipto. El contagio de la oftalmía egipcia por las moscas" y "Origen del Egipto"; y en 1909 "Momificación y embalsamamiento en tiempo de los Faraones", obra de gran interés, en la que no nos vamos a detener ya que el médico gaditano en sus descripciones utiliza los apuntes de Herodoto, Diodoro y de egiptólogos como Mariette, Toda, Loret y Maspero, que por conocidos sería reiterativo exponerlos aquí; apuntaremos solamente que siguiendo a Herodoto dedica buena parte del opúsculo a las tres clases de embalsamamientos existentes: la realizada a los ricos, a los de mediana fortuna y a los pobres.

En el mismo año, 1909, publicó en el Boletín de la Real Academia de la Historia, institución de la que era Correspondiente, un informe titulado "Objetos egipcios encontrados en Tarragona”. Comienza su narración, como no podía ser de otra manera, con el recuerdo al ilustre arqueólogo Juan Fernández de Velasco que en 1852 adquirió unos terrenos en la Colina Rocosa, donde se asienta Tarragona, en un lugar denominado Bosch Negre. Fernández de Velasco tenía indicios de que en esos terrenos podía realizar importantes hallazgos arqueológicos y no se equivocó: "En el transcurso de las obras (...) halláronse gran número de objetos y varios restos de edificaciones antiquísimas, como cimientos, pavimentos, mosaicos, etc., y por bajo de éstos, y en capas superpuestas, monumentos de otros pueblos más antiguos". Fernández de Velasco formó una colección con este material, aunque envió algunos objetos al Museo Arqueológico provincial. Rodolfo del Castillo visitó Tarragona en febrero de 1908, época en que la citada colección estaba custodiada por Juan Manuel Martínez, hijo político de Fernández de Velasco, que facilitó la visita al médico gaditano. Del Castillo se fijó en tres ejemplares "que á nuestro entender, tenían todos los caracteres de los de la civilización egipcia, como son un Respondiente, un Escarabajo sagrado y una estatua en bronce de la diosa Isis amamantando a Horo". Estos objetos fueron analizados también por Manuel Treviño, notable estudioso español de la egiptología, que corroboró que eran egipcios " $y$ de una autenticidad indiscutible". Rodolfo del Castillo no se conformó y recabó la opinión de su maestro y amigo, ya citado aquí, Víctor Loret, gran especialista en el Egipto Antiguo, autor de una gramática egipcia y profesor de la Facultad de Letras en la Universidad de Lyon. Loret "nos lo confirmó sin ningún género de reserva”. He aquí un importante testimonio de relación directa de Rodolfo del Castillo con una notable figura de la egiptología europea, circunstancia que se vería facilitada por su dominio del francés y evidentemente por el apasionamiento que sentía por los estudios arqueológicos. Con 
su apreciación personal y el apoyo de Treviño y de Loret, Rodolfo del Castillo define estos objetos como funerarios, lo que le lleva a realizar una síntesis sobre el destino del individuo después de la muerte, la momificación de los cadáveres, el entierro y el ritual funerario en el Egipto Antiguo.

En cuanto a estos objetos, muy resumidamente, podemos apuntar lo siguiente. La estatua Respondiente (de barro cocido, barnizado de un color verde nilo y de 16 centímetros de altura) según del Castillo era de las que solían usarse en los tiempos de la XXVI dinastía; representaban estas estatuas a criados y servidores que debían responder al llamamiento del difunto cuando éste los necesitara en sus labores o para ayudarle en los trabajos que le mandase ejecutar Osiris. En cuanto al escarabajo sagrado se le representa en la forma de un hombre con cabeza de escarabajo; en el coleóptero se encarna a un dios que representa el emblema de la vida humana y de las transformaciones sucesivas del alma en el otro mundo. El hallado en Tarragona está labrado en ágata oscura y "ha debido servir de sello ya montado en una sortija o en otro adorno que llevara su poseedor como amuleto". Hay otro matiz importante que resalta del Castillo sobre la importancia de este coleóptero en la civilización egipcia, al margen del ya apuntado de su uso como amuleto:

"Entre los egipcios el corazón no era únicamente el lugar donde residía la fuerza y la vida, sino que también se creía que era el originario de las buenas y malas acciones. Aceptando el simbolismo del insecto de intervenir en la resurrección de los cadáveres, al extraer el corazón de éstos en el momento del embalsamamiento, se colocaba en su lugar sobre el pecho un escarabajo labrado en piedra dos ó tres veces mayor del tamaño del natural,...”.
$\mathrm{Y}$, por último, la tercera figura corresponde a la diosa Isis, esposa de Osiris (de bronce y de 9 centímetros de alto), que está sentada amamantando a Horo y lleva sobre su cabeza los signos emblemáticos del Sol y la Luna. Isis recibió el título de señora de los encantamientos $\mathrm{y}$ asumía varios as-

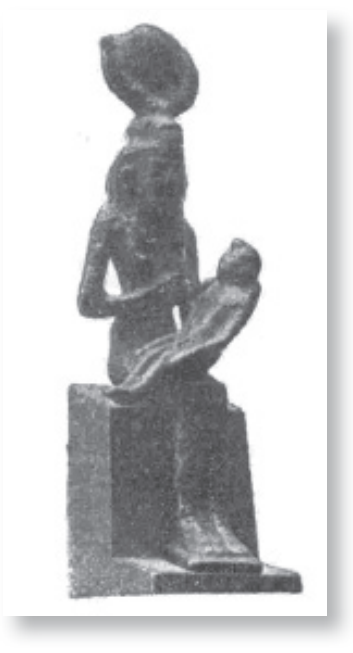

Figura 2: La diosa Isis amamantando a Horo (Fuente: $R$. del Castillo, 1909c). pectos, aunque el más recordado por los egipcios era el de madre divina como se puede ver en la figura que reproducimos (figura 2).

Rodolfo del Castillo, en esta importante comunicación a la Real Academia de la Historia, hace matizaciones muy interesantes sobre estos objetos funerarios, como hemos podido apreciar; pero también matiza que no son los únicos hallados en España, como por ejemplo dos Respondientes aparecidos en excavaciones hechas en Cádiz, remitiendo al estudio realizado sobre los mismos por Manuel Rodríguez Berlanga en la "Revista de Archivos". En Cádiz también, en el descubrimiento de una tumba en 1885, aparecieron algunos "escarabajos", "tales como uno de ágata montado en una sortija de oro (...) lleva grabada en su parte plana una diosa, que posee el Dr. D. Cayetano del Toro". Recuérdese que se refiere al eminente oftalmólogo y político gaditano Cayetano del Toro y Quartiellers, pariente y maestro en la especialidad de Rodolfo del Castillo. Asimismo en excavaciones del gaditano barrio de 
Santa María se hallaron unas tumbas y en ellas dos escarabajos con inscripciones en su parte plana, estudiados por Pedro Riaño de la Iglesia, director de la Biblioteca Provincial y Museo Arqueológico de Cádiz y Correspondiente de la Real Academia de la Historia.

Nuestro médico, en febrero de 1909, era muy consciente de que se iban multiplicando los hallazgos arqueológicos en España (Ibiza, Villaricos y Herrerías en Almería, Cádiz y Bares en la provincia de la Coruña), y de la influencia de Egipto en la civilización del Occidente de Europa, incluida España, "pero en qué grado, en qué tiempos y por cuántas maneras se difundió sobre el suelo ibérico, importa averiguarlo bien". No le faltaba la razón al médico gaditano.

\section{LA OFTALMOLOGÍA EN TIEMPOS DE LOS GRIEGOS Y DE LOS ROMANOS}

En este apartado nos vamos a referir a dos monografías: "La oftalmología en tiempo de los griegos" (1910) y "La oftalmología en tiempo de los romanos" (1905). Centrémonos primero en Grecia. Una de las primeras citas se refiere a Hipócrates y las enfermedades de los ojos, pero esto constituye sólo un apunte, porque el interés del médico gaditano se centra en un papiro relacionado con la oftalmología, fragmento de un tratado de Cirugía. La datación cronológica del papiro es ambigua, tan sólo se apunta que hasta la época de Alejandro no se introdujo en Grecia el papiro, y que las obras se escribían en tablas enceradas y pieles de animales. En este capítulo encontramos nuevamente la presencia de las relaciones científicas internacionales establecidas por Rodolfo del Castillo, ya que el papiro está en posesión de un amigo personal, Adolphe Cattaui, del Cairo, "el cual lo tiene depositado en la Biblioteca de la Universidad Egipcia". Este documento fue estudiado por J. Nicole y comentado por Johannes Ilbergs, apoyándose sobre todo del Castillo en sus descripciones en el primero de estos autores. Este fragmento tiene tan sólo 18 centímetros de alto y 14 y medio de ancho, y proporciona información de un tratamiento quirúrgico practicado por los griegos en determinadas afecciones oculares. Leamos:

"El fragmento del papiro (...) proviene de un curioso capítulo de la Oftalmología griega, que ya en los escritos de Hipócrates se recomienda en las enfermedades de los ojos al practicar en ciertos casos una ó varias incisiones en la piel de la cabeza, que tienen lugar en la dirección de los ojos, pretendiendo por medio de estas sangrientas incisiones desviar el reuma. Según Celso, el tratamiento quirúrgico de estas enfermedades era muy conocido, y Filoxenos, en Alejandría, simplificó y perfeccionó la práctica de estas operaciones quirúrgicas contra el reuma de los ojos. Conocíanse dos procedimientos, que se denominaba Hipostatismo (...), y Periscytismo (...), términos que se encuentran en los escritos de Aetios de Amida y Paulos de Egina...”.

Celso, por ejemplo, aclara que las infecciones de la conjuntiva ocular son atribuidas al "reuma", y que los exudados de los ojos provienen de la "pituita" que se desliza a través de los vasos " $y$, en muchos casos, se curan practicando determinadas incisiones en la piel de la cabeza". Como se puede comprobar las ideas etiológicas y la terapia quirúrgica están en consonancia con la consabida doctrina humoral. Rodolfo del Castillo explica estas técnicas apoyándose en las descripciones de Celso. Algunos cirujanos, en Grecia, practicaban nueve incisiones sobre el cuero cabelludo: dos en línea recta hasta el occipital, divididas por una incisión transversal; dos por debajo de las orejas, separadas por otra línea igualmente transversal, y las tres últimas siempre en línea 
recta, dirigiéndose desde el vértice del cráneo a la frente. Esta técnica tiene algunas variantes, que no entramos a detallar. Galeno cita en sus obras el "Hipospatismo" como operación relativamente más fácil: "Se hacían en la frente tres incisiones verticales $y$ paralelas, $y$ del largo de dos pulgadas, hasta el hueso, y distanciadas tres pulgadas unas de otras, con ayuda de una sonda de paleta de dos filos, formando un puente de piel, y los vasos de éste se separaban por medio de un bisturí". Precisamente el contenido del papiro mencionado está en consonancia con los apuntes realizados, "y no hay descripción más detallada del Periscytismo como del Hipospatismo". Aunque también se describen ambas técnicas siguiendo los textos de Pablo de Egina (siglo VII). Nuestro médico resume el asunto así:

"Por lo expuesto venimos en conocimiento que afecciones de los ojos eran consideradas por los médicos griegos como de origen reumático y de difícil curación, en que era necesario recurrir á actos quirúrgicos como el Hipospatismo y el Periscytismo, siendo este último el más cruento (...). El fragmento del papiro que nos ocupa es un testimonio auténtico e indiscutible de lo que era la cirugía ocular en tiempo de los griegos, y se viene en conocimiento que desde un siglo antes de Jesucristo el contenido de nuestro papiro es proclamado en todos los Tratados de Cirugía de su época y hasta en tiempo de los romanos...".

Del Castillo no entra en los aspectos filológicos y remite a los trabajos de Nicole e Ylbergs, sin embargo no omite las cuestiones prácticas (etiológicas y quirúrgicas) que afectan a las "teorías reumáticas de las oftalmías". Como especialista en oftalmología y estudioso pertinaz de la historiografía médica quiere comprender estas técnicas quirúrgicas en su contexto, aunque estén obsoletas o sean juzgadas como "extravíos de la ciencia médica", por eso quizás se sorprende "que el ilustre historiador de la Oftalmología, J. Ylbergs, omita el entrar en detalles respecto á estos procedimientos operatorios en su edición del Libro VII de Aetios". No cabe duda de que el médico gaditano consigue fraguar en esta breve monografía un interesante trabajo de alta divulgación, exponiendo sintéticamente los fundamentos médicos y quirúrgicos de estos problemas oftalmológicos.

Hemos dejado para el final, por coherencia cronológica y por su importancia historiográfica, la monografía dedicada a la oftalmología en tiempos de los romanos, publicada en 1905 y que fue traducida al alemán por Max Neuburger en 1907; también existe una edición resumida publicada en 1956 con motivo del "II Congreso Latino de Oftalmología". En esta monografía encontramos varios capítulos, por ejemplo: la medicina en Roma, los sellos de los oculistas, las inscripciones tumulares de médicos oculistas romanos, los colirios y sus denominaciones o las maneras de usar los colirios y la terapéutica. Esta monografía por sí sola requeriría un estudio monográfico, pero el objetivo que nos hemos planteado en este artículo es el de ofrecer una visión general de los estudios historiográficos de Rodolfo del Castillo, por este motivo centraremos nuestros comentarios en los sellos de los oculistas, las inscripciones tumulares y los colirios, aunque no sin advertir que la preocupación del médico gaditano por el tema viene desde años atrás cuando publicó en 1897 un interesantísimo opúsculo titulado "Epigrafía oftalmológica hispano-romana", y en el mismo año, en los "Anales Médicos Gaditanos", otro trabajo que trata sobre "Un oculista gaditano del tiempo de la dominación romana en España", y en 1902 sobre dos nuevos sellos de oculistas greco-romanos, claros precedentes de la citada 
monografía, que fue calificada por Fidel Fita Colomé (1835-1918) -notable arqueólogo que hizo de la epigrafía romana una disciplina independiente en la historiografía española- de original y de relevante mérito.

Es sabido que los oculistas se denominaban "Ocularii clinici" y "Ocularii chirurgi", según sus prácticas fueran médicas o quirúrgicas. Apunta del Castillo, con cierto tono apasionado, que gracias a las inscripciones (la epigrafía), los instrumentos, los medicamentos y diversos objetos hallados en las excavaciones, "se demuestra plenamente que ninguna especialidad aventajó a la oculística" (figura 3).

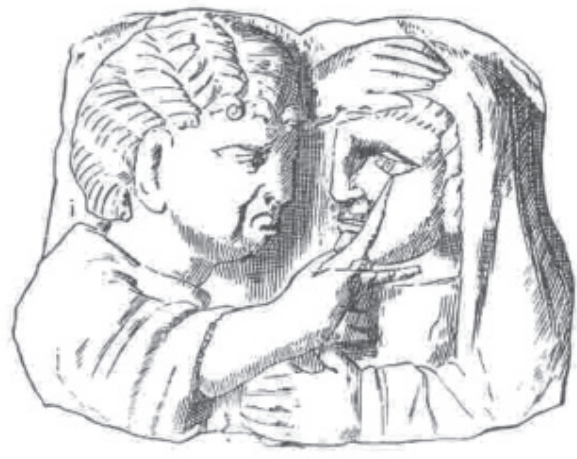

Figura 3: Un oculista explorando o interviniendo a una persona (Fuente: R. del Castillo, 1956).

El primer asunto, pues, es el de los sellos de los oculistas, relacionados directamente con los colirios. La única garantía que tenía el público "era que el medicamento fuese refrendado con el nombre del oculista", y esto se hacía con un sello que cada oculista poseía, "que era de una piedra especial finamente labrada"; su forma era normalmente cuadrangular o rectangular, "de dimensiones variables, entre 60 milímetros de largo, 35 de ancho y 15 de espesor".
Estos sellos llevaban grabados el prenombre, el nombre y el cognombre del oculista, el colirio, las principales sustancias de su composición y la indicación médica de las enfermedades en que se debían utilizar, además de los líquidos en que se debían disolver e incluso las veces en que se debían aplicar. Por ejemplo: "Colirio divino de Cayo Dedemon contra el lagrimeo sintomático de la oftalmía; se harán tres aplicaciones, diluyéndolo en clara de huevo". En la monografía abundan los ejemplos, eficazmente complementados con las ilustraciones correspondientes. Los casos expuestos son muy variados y proceden de diversos lugares como, por ejemplo, la Galia, la Bretaña y las Germanias, y se fundamenta el estudio crítico en las opiniones de autoridades en materia de epigrafía oftalmológica como Sichel o Deneffe, autor este último de la obra "Los oculistas Galo-Romanos". Del Castillo dedica un breve capítulo al de "Caelius Diadumenus", conocido como "sello de Madrid", aunque las indagaciones de P. Fita no consiguieron aclarar donde fue localizado. Del Castillo supone que Caelio Diadumeno pudo venir de un pueblo de la Galia a Tarragona, aunque esto lo apunta más desde la especulación que desde la certeza. Deja, pues, abierto este asunto:

"Si el problema de los orígenes de estos sellos queda aún en pie, en cambio cada sello ha sido una página de la historia de la oftalmología del tiempo de los romanos, que nos ha revelado el nombre de un gran número de oculistas, colirios que usaba, substancias medicinales que entraban en su composición, enfermedades a que se aplicaban...".

No cabe duda de que las inscripciones tumulares de los médicos oculistas romanos es una fuente indiscutible para evidenciar su existencia. Normalmente en estas inscripciones se observa que todos los médicos oculistas 
eran libertos, excepto en algún caso de esclavo imperial. Los ejemplos que cita Rodolfo del Castillo también son abundantes y no cabrían en este artículo, citaremos algunos a modo de ejemplo: "Marco Geminio Felice, liberto de Marco, médico oculista, en la encrucijada de los ajos" o "Aquí yace para siempre Ilustrio? Celadiano, esclavo de Tiberio César Augusto, médico oculista, afectuoso para sus padres. Vivió treinta años". O bien este otro que fue localizado en Chiclana de la Frontera (Cádiz), de la primera centuria de la era cristiana en tiempos de Augusto: "Consagrado a los Dioses Manes. Aquí yace Albanio Artemidoro, médico oculista, de 46 años, querido de los suyos. Séale la tierra ligera" (figura 4).

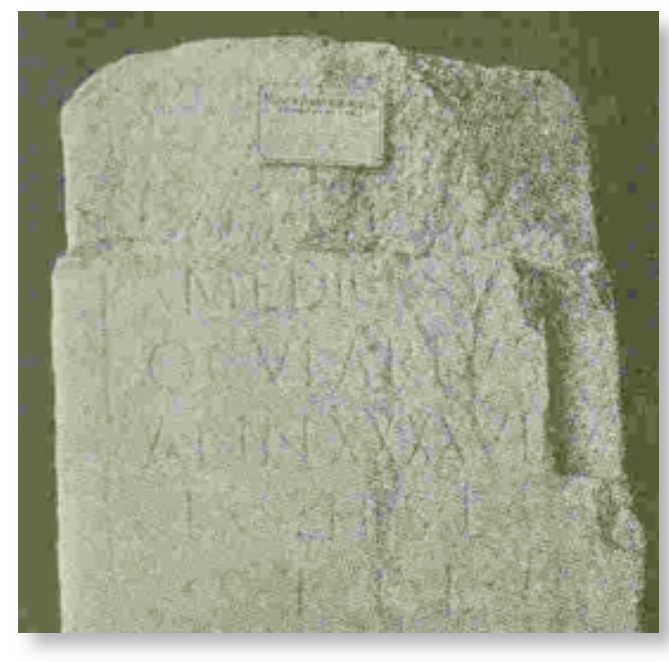

Figura 4: Túmulo funerario de Albanio Artemidoro (Fuente: Rodolfo del Castillo, 1956).

Ya en 1903, Rodolfo del Castillo, publicó un folleto titulado "Los colirios oleosos en la antigüedad", y en su monografía dedica un capítulo titulado "Los colirios y sus denominaciones", aclarando lo siguiente: "Cuando estas complicadas combinaciones, bien en sólido o líquido, eran destinadas a ser introducidas en alguna cavidad natural o accidental, recibian el nombre genérico de colirios, que no era, como es hoy, una fórmula exclusiva destinada al tratamiento de las enfermedades de los ojos". Las sustancias eran finamente pulverizadas y si se les quería dar consistencia de pasta se les adicionaba para ello goma, agua o alguna otra sustancia con propiedades aglutinantes: "Hecha la pasta, se le daba la forma de pequeñas barras, la que antes de desecarse, que se hacía a la sombra, se le imprimía la inscripción con el sello del oculista que había ideado la fórmula, o el del que lo expendía, constituyendo esto un colirio de los llamados secos". Además había otros colirios denominados líquidos, y por último a los que se les daba forma de pomadas o ungüentos, los cuales se conservaban en cajas metálicas.

Los colirios secos, en el momento de su empleo, se pulverizaban y se disolvían en el líquido que convenía, siendo por lo regular agua de rosas, aceite, vino ligero o vinagre, "cuando se quería suavizar su acción astringente, se daba entonces la preferencia a la clara de huevo o a la leche de mujer". Cuando los colirios eran disueltos se introducían dentro del ojo, sirviéndose para ello de pinceles o espátulas". Los colirios secos también eran aplicados en el interior del ojo en forma de polvo fino. Esta aplicación se hacía por insuflación o con una cucharilla. Dioscórides cita como ejemplo el uso de la jibia calcinada y reducida a polvo: "molido con sal y echado, consume las uñas que en los ojos se engendran". Los colirios líquidos eran aplicados en instilaciones, o gota a gota, empleando la esponja o la lana finamente cardada, o bien vertiendo el líquido directamente desde el vaso, o bien por medio de cucharillas. En cuanto a los ungüentos se utilizaban "como unturas alrededor del ojo y no en su interior". Los ungüentos eran menos consistentes 
que las pomadas, "entrando en su composición la pulpa de manzanas y las grasas animales". Normalmente antes de poner algún colirio, los ojos eran cuidadosamente lavados con una decocción de mirra o de hojas de rosa, a fin de limpiarlos adecuadamente y suprimir exudados. Eran muy usados los colirios preparados con sales de cobre.

\section{EPÍLOGO}

Rodolfo del Castillo y Quartiellers, médico gaditano, se especializó en oftalmología, y realizó una importante labor médica en Córdoba y en Madrid; en esta ciudad fue profesor de enfermedades de los ojos en el Instituto fundado por el afamado cirujano portuense Federico Rubio y Gali (1827-1902). Realizó una importante obra como traductor de textos médicos, por ejemplo "Las heridas del ojo" de Arlt, las "Lecciones oftálmicas" de Sous o "Los elementos de terapéutica ocular" de Bourgeois. Colaboró en revistas como "El Progreso Médico" o "La Crónica Oftalmológica", ambas de Cádiz, fundó en Córdoba "La Andalucía Médica" y en Madrid los "Anales de Oftalmología”. Además de ser congresista y senador.

En cambio son menos comentadas, en cuanto a su contenido, las aportaciones que realizó a la historiografía médica de la Antigüedad, que hemos tratado de glosar en este artículo, y que merecieron en su día también la atención del profesor Orozco Acuaviva. Rodolfo del Castillo fue una rara excepción en la medicina española de la época, ya que sí era frecuente -quizás por influencia de los tratados de medicina franceses- que los autores realizaran una introducción histórica de los temas tratados en sus libros, pero más raro es encontrar a autores que estudien la bibliografía nacional y extranjera de historiadores y arqueólogos para realizar trabajos de investi- gación y de alta divulgación sobre temas tan minoritarios y especializados como pueden ser la medicina mesopotámica, egipcia, griega y romana. El historiador de la Medicina vienés Max Neuburger (1868-1955) tradujo al alemán la monografía que Rodolfo del Castillo dedicó a la oftalmología en tiempos de los romanos. Neuburger fue fundador nada menos que del Instituto de Historia de la Medicina y seguidor de una concepción de la historia de la cultura semejante a la de su maestro Puschmann, que asoció -como bien ha indicado López Piñero- a una concepción biologista del cambio histórico, sirviendo de base a su exposición de conjunto de la historia antigua y medieval. Se debe reconocer, pues, a Rodolfo del Castillo la condición de estudioso en España de la medicina antigua, mereciendo incluso el reconocimiento internacional con la citada traducción del historiador vienés. Para terminar no podemos olvidar que hace muchos años el gran historiador Luis García Ballester señaló el gran interés de Federico Rubio y Gali por la historiografía médica al introducir en su "Revista Iberoamericana de Ciencias Médicas" trabajos de esta disciplina, concibiéndola "como disciplina médica, no como un diálogo con los muertos". En esta revista colaboraron Martínez Vélez, Luis Comenge y también Rodolfo del Castillo, del que dice García Ballester: "Allí colaboró Rodolfo del Castillo Quartiellers, profesor de Oftalmología en el Instituto, con un sólido artículo, basado en fuentes arqueológicas y epigráficas, sobre 'La oftalmología en tiempos de los romanos' (1900) donde resume las investigaciones propias (1896) y ajenas sobre el tema". La misma circunstancia acontece en los "Anales Médicos Gaditanos", revista liderada por Cayetano del Toro, que también acogió en sus páginas artículos de Rodolfo del Castillo sobre los oculistas en tiempos de los romanos. 


\section{FUENTES}

- Expediente de Rodolfo del Castillo y Quartiellers. Legajo L, expediente 4 (Archivo de la secretaría de la Facultad de Medicina de Cádiz).

- Castillo y Quartiellers, R. del: “Ejercicios del doctorado del licenciado D. Rodolfo del Castillo y Quartiellers. Tesis. Sífilis, naturaleza y sitio" (Cádiz 6 de junio de 1872). Cuadernillo de 38 pp. Cosidas a hilo (210 x 140 mm.) estando las páginas 2 y 24 a 38 en blanco y el texto en letra de grafía del siglo XIX. Legajo L, expediente 4 (Archivo de la secretaría de la Facultad de Medicina de Cádiz).

- Castillo y Quartiellers, R. del (1897): Epigrafía oftalmológica hispano-romana. Imprenta y Librería del Diario de Córdoba. Córdoba (Biblioteca de la Facultad de Medicina de la Universidad Complutense de Madrid, en adelante BFMUCM).

- Castillo y Quartiellers, R. del (1903): Los colirios oleosos en la antigüedad. Administración de la Revista de Medicina y Cirugía Prácticas. Madrid (BFMUCM).

- Castillo y Quartiellers; R. del (1904): El Código de Hammurabi y la oftalmología en los tiempos babilónicos. Administración de la Revista de Medicina y Cirugía Prácticas Imprenta y Librería de Nicolás Moya. Madrid (BFMUCM).

- Castillo y Quartiellers, R. del (1905): La oftalmología en tiempos de los romanos. Establecimiento. Establecimiento tipográfico de Idamor Moreno. Madrid (BFMUCM).

- Castillo y Quartiellers, R del (1907): Die Augenheilkunde in der Romerzeit. Autorisierte ubersetzung aus dem spanischen von Max Neuburger. Leipzig und Wien.

- Castillo y Quartiellers, R. del (1956): La oftalmología en tiempos de los romanos. Laboratorios del Norte de España, SA. Masnou, Barcelona (Colección particular F. Herrera).

- Castillo y Quartiellers, R. del (1907): La esterilización de las aguas del Nilo en el siglo XI. Establecimiento tipográfico de Idamor Moreno. Madrid (BFMUCM).

- Castillo y Quartiellers, R. del (1908): La medicación oleosa en tiempo de los faraones. El aceite de ricino. Administración de la Revista de Medicina y Cirugía Prácticas. Madrid (BFMUCM).
- Castillo y Quartiellers, R. del (1909a): Momificación y embalsamamiento en tiempo de los faraones. Administración de la Revista de Medicina y Cirugía Prácticas. Madrid (BFMUCM).

- Castillo y Quartiellers, R. del (1909b): “Momificación y embalsamamiento en tiempo de los faraones". Revista de Medicina y Cirugía Prácticas: LXXXIII, 1.074, pp. 209-224.

- Castillo y Quartiellers, R. del (1909c): “Objetos egipcios encontrados en Tarragona”. Boletín de la Real Academia de la Historia: LIV, III, pp.169-180 (BFMUCM).

- Castillo y Quartiellers, R. del (1910): La oftalmología en tiempo de los griegos. Administración de la Revista de Medicina y Cirugía Prácticas. Madrid (BFMUCM).

\section{BIBLIOGRAFÍA}

- Abascal, J.M. (1996) Fidel Fita y la epigrafía hispano-romana. Boletín de la Real Academia de la Historia: 193-2: 305-334.

- Bishop, W.J. (1963) Cirugía histórica. Editorial Mateu. Barcelona.

- Borobia, E.L. (1988) Instrumental médico-quirúrgico en la Hispania Romana. Impresos Numancia SA. Madrid.

- Buzzi, A. y Doisenbant, A.R. (2008) Evolución histórica de la medicina. Editorial Médica Panamericana. Buenos Aires: 41-53.

- Cassin, E.; Bottero, J. y Vercoutter, J. (1984) Los Imperios del Antiguo Oriente. Del Paleolítico a la mitad del segundo milenio. Siglo XXI de España editores, SA. Madrid.

- Fita, F. (1906): La oftalmología en tiempos de los romanos. Boletín de la Real Academia de la Historia: 49: 279-280.

- Fresquet, J.L (2009) Max Neuburger (1868-1955) Disponible en http://www.historiadelamedicina.org/neuburger.html (consultado el 1 de julio de 2012).

- García-Ballester, L.: Lo clásico en la medicina española moderna y contemporánea. Conferencia mecanografiada Disponible en http://www.bduimp.es/ archivo/conferencias/pdf/0407_83_10040_07_Garcia_ Clasico:idc15590.pdf (consultado 1 de julio de 2012).

- Gómez-Vila, J. (2000) Epigrafía romana. Pautas sobre o seu tratamento didáctico Revista Galega do Eusino: 29: 177-193. 
- Granjel, Luis S. (1986) Medicina española contemporánea. Ediciones Universidad de Salamanca: 201.

- Guerra, F. (1982) Historia de la Medicina. Ediciones Norma, SA. Madrid. Tomo 1: 68-69.

- Haeger, K. (1993) Historia de la Cirugía. Editorial Raíces. Madrid, pp. 17-20.

- Herrera, F. y Cabrera, JR (1986): La tesis doctoral sifilográfica de Rodolfo del Castillo y Quartiellers (18451917). Anales de la Real Academia de Medicina y Cirugía de Cádiz: XXII (1): 73-81.

- Herrera, F.(1984) Grados de doctor y tesis doctorales en la Facultad de Medicina de Cádiz. Tesis de licenciatura (Ejemplar mecanografiado). Facultad de Medicina de Cádiz.

- Herrera, F. (1987) Las opiniones de Rodolfo del Castillo y Quartiellers (1845-1917) sobre el Código de Hammurabi y la oftalmología en los tiempos babilónicos (1904).

- Anales de la Real Academia de Medicina y Cirugía de Cádiz: XXIII (1): 21-32.

- Herrera, F. (2002) Federico Rubio y la renovación de la medicina española (1827-1902). Ayuntamiento de El Puerto de Santa María. El Puerto de Santa María.

- Herrera, F. (2002) Un acercamiento a la obra de Federico Rubio y Gali (1827-1902). Revista de Historia de El Puerto: 29: 63-88.

- Herrera, F. (2010) "Cayetano del Toro y Quartiellers" (1842-1915). En Bustos, M.: Centenario de la Real Academia Hispano Americana de Ciencias, Artes y Letras (1910-2010). I. Alrededor de los Cien Años de Historia y Vida Académicas. Real Academia Hispano Americana de Ciencias, Artes y Letras. Cádiz, pp. 207-236.

- Javierre, J.M. (dir.) (1979) Gran Enciclopedia de Andalucía. Sevilla, t. II, p. 755.

- Laín, P. (1982): Historia de la Medicina. Salvat editores, SA. Barcelona.

- Lara, F. (1982): Código de Hammurabi. Editora Nacional. Madrid.

- López Piñero, J.M. (1984) Los estudios historicosociales sobre la medicina. En Lesky, E: Medicina Social. Estudios y testimonios históricos. Ministerio de Sanidad y Consumo. Madrid: 9-30.

- Monteagudo, L. (2000) La cirugía en el Imperio Romano. Anuario Brigantino: 23: 85-150.
- Nunn, J.F. (2002) La medicina del Antiguo Egipto. Fondo de Cultura Económica. México.

- Orozco, A. (1971) Apuntes para la historia de la medicina gaditana. Anales de la Real Academia de Medicina y Cirugía de Cádiz. VI/ 1:. 7-79.

- Orozco, A. (1978) Médicos escritores gaditanos. Excmo. Colegio Oficial de Médicos de Cádiz:. 69-75.

- Orozco, A. (1982) El gaditano Rodolfo del Castillo (1845-1917) y "La Andalucía Médica" de Córdoba (1876-1891). Boletín Informativo del Excmo. Colegio Oficial de Médicos de la Provincia de Cádiz: 8: 16-19.

- Orozco, A. (1984) Tres etapas históricas de la Ética Profesional de Enfermería. Boletín Informativo del Excmo. Colegio Oficial de Médicos de la Provincia de Cádiz: 2: 9.

- Orozco, A. (1996) Rodolfo del Castillo (1845-1917) y la medicina cordobesa. Actas del VII Congreso de Academias de Andalucía (Córdoba, 17-19 mayo 1996). Instituto de Academias de Andalucía y Real Academia de Córdoba de Ciencias, Bellas Letras y Nobles Artes. Córdoba: 189-200.

- Padró, J. (1986) La formación de los grandes estados mesopotámicos. En Moretón, C. (dir.): Gran Historia Universal. IV: Egipto y los Grandes Imperios. Club Internacional del Libro. Madrid: 86-97.

- Zaragoza, J.R (1972) La medicina de los pueblos mesopotámicos. En Laín, P. (dir.): Historia Universal de la Medicina. Salvat editores, Barcelona. 